\title{
THE PATHOLOGY OF INFLAMMATORY BOWEL DISEASE
}

\author{
DR B C MORSON, MA, DM, FRCPath \\ St Mark's Hospital, London
}

It is customary to include under the general heading of Non-specific Inflammatory Bowel Disease both Crohn's Disease and ulcerative colitis and to exclude the dysenteric disorders. In my opinion, Crohn's disease and ulcerative colitis should be considered separately as if they were different diseases, but it is important to bear in mind that the dysenteric types of inflammation come almost daily into the differential diagnosis of these two non-specific inflammatory bowel disorders.

The study of sequential reatal biopsies in ulcerative colitis (Table I) has proved

Table I

Rectal biopsy in ulcerative colitis: salient features

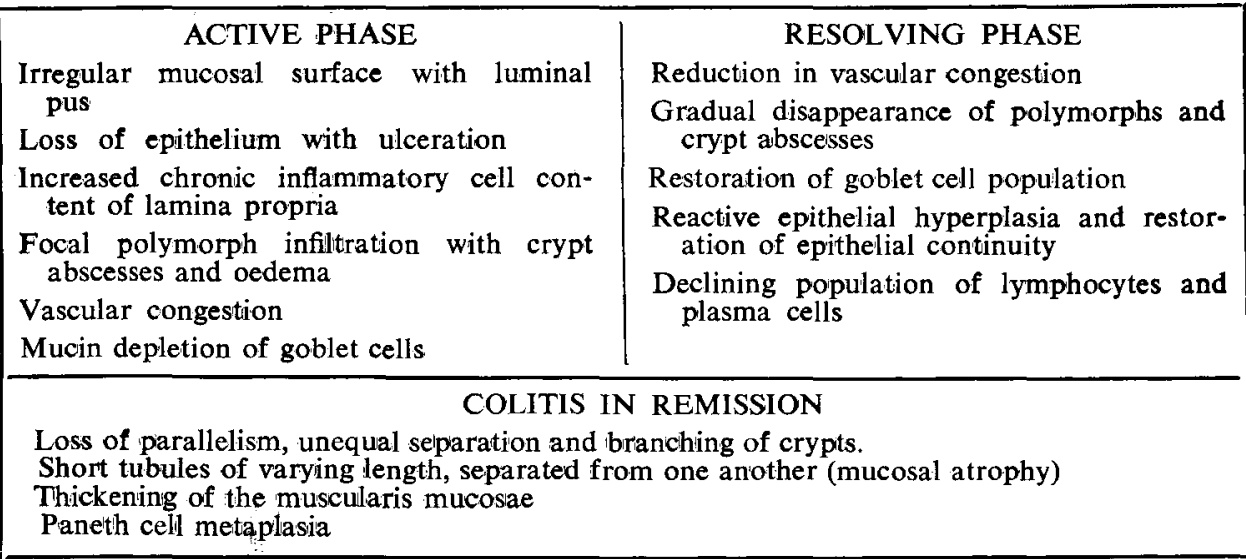

to be very valuable in the assessment of histological criteria for diagnosis and response to treatment (Morson $\left.{ }^{1}\right)$. In active ulcerative colitis there is diffuse infiltration, predominantly mononuclear, but also with aggregates of neutrophils, some forming crypt abscesses and the whole accompanied by epithelial hyperplasia with mucin depletion. If the histology of the disease is followed as it goes into remission the first changes are the disappearance of polymorphs and the gradual restoration of the goblet cell population but it is only after many weeks of treatment that the chronic inflammatory cell infiltration disappears and the epithelium becomes completely normal. Finally a mucosa remains which is normal only in the sense of showing no inflammation but in which there is often loss of parallelism of crypts with branching and an irregular architecture together with a thickened 
muscularis mucosae. This is a pattern of mucosal atrophy which is almost diagnostic of chronic ulcerative colitis in remission.

The pathologist can only make a diagnosis of ulcerative colitis with confidence if he observes the disease in its active stage or when it is in remission with mucosal atrophy. It is in the resolving phase that the histology of ulcerative colitis is least specific and the appearances are difficult to separate from other inflammatory disorders. An increasing number of patients with ulcerative colitis are coming to hospital having had some treatment and it is my impression that this accounts for the frequency with which a first biopsy shows features of resolving colitis which can be difficult to distinguish from the histology of biopsies in Crohn's disease. The value of sequential biopsy lies in the opportunity to compare the histology seen at intervals of time and this will often clarify a diagnosis which was obscure in the first biopsy. If a pathologist feels the interpretation of the first biopsy is equivocal then he should say so and request a second or even a third examination by which time he will have accumulated sufficient knowledge of the histology to make his interpretation more accurate.

Another difficulty in initerpretation is found when polymorphs are seen infiltrating epithelium but the goblet cells are well preserved. This is unlike ulcerative colitis but is seen in Crohn's disease. However, it is also an important feature of the biopsy appearances in infective colitis. This encompasses not only Salmonella colitis, which can cause total colitis and is occasionally quite a severe disease but also Shigellosis which is usually a distal colitis and is seldom severe, Gonococcal proctitis and, of course, amoebic dysenttery. There are common histopathological features in the mucosa to all these forms of infective colitis and they are dominated by the following features: oedema and the presence of neutrophils, but without any marked distortion of crypt architecture, relatively good preservation of the goblet cells and what is most important, no considerable or dominant increase in the chronic inflammatory cell population of the lamina propria. In non-specific inflammatory bowel disease the most persistent and reliable feature is the increase in the number of lymphocytes and plasma cells in the lamina propria, whereas this is nothing like so marked in infective colitis.

In Crohn's disease with rectal involvement the crypts are not distorted and a reflection of this architectural preservation is the presence of normal goblet cells despite infiltration of the epithelium by neutrophils (Shove and Morson ${ }^{2}$ ). However, unlike infective colitis, there are increased numbers of both lymphocytes and plasma cells in the lamina propria and this inflammatory infiltrate often varies in intensity in different parts of the mucosa. Aggregates of lymphocytes typically seen in relation to the base of crypts, are characteristic. A further feature which may be present to help in the differentiation from infective colitis is disproportionate inflammation with increased numbers of inflammatory cells in the submucosa compared to the mucosa (Dyer, Stansfeld and Dawson ${ }^{3}$ ). The presence of non-caseating granulomas consisting of epithelioid cells and giant cells in the mucosa or submucosa is the strongest evidence for a diagnosis of Crohn's disease, but often small focal collections of histiocytes (microgranulomas) are present in the absence of a well-defined granuloma.

A comparison of the main distinguishing features between ulcerative colitis, 
Table II

Histological features which aid in the differentiation of infective colitis, active ulcerative colitis and Crohn's disease

\begin{tabular}{|c|c|c|c|}
\hline Histological features & $\begin{array}{l}\text { Infective } \\
\text { colitis }\end{array}$ & $\begin{array}{c}\text { Active ulcerative } \\
\text { colitis }\end{array}$ & $\begin{array}{l}\text { Crohn's } \\
\text { disease }\end{array}$ \\
\hline Mucosal oedema & ++ & + & ++ \\
\hline Vascularity & + & +++ & + \\
\hline $\begin{array}{l}\text { Mucosal inflammation } \\
\text { (a) polymorphs } \\
\text { (b) mononuclear cells }\end{array}$ & $+\underset{ \pm}{+}+$ & $t^{+}++$ & $+\stackrel{+}{+}+$ \\
\hline Distortion of crypt architecture & - & +++ & + \\
\hline Mucus depletion & \pm & +++ & \pm \\
\hline
\end{tabular}

Crohn's disease and infective colitis is given in Table II. By and large the histology of infective colitis is dominance of polymorphs with oedema in the absence of distortion of crypt architecture or much mucus depletion, in contrast to active ulcerative colitis in which although polymorphs may be increased in number, there are large numbers of mononuclear cells, much distortion of crypt architecture and, of course, this very important issue of mucus depletion which a numerical taxonomy study at St. Mark's showed was a very sensitive indicator of active ulcerative colitis (Hywell Jones et $\mathrm{ll}^{4}$ ).

I would like to turn now to consider the significance of granulomas in Crohn's disease. Recent research at St. Mark's has attempted quantitation of granulomas in relation to prognosis and the aetiology of the disease (Chambers and Morson ${ }^{5}$ ). The number of granulomas in sections of involved bowel has been counted and related to length of previous history, treatment with steroids, site of involvement and the subsequent course of the disease. It was found that a high content of granulomas predicted a good prognosis in the large bowel and anus, but was of no prognostic significance in the small bowel. A large regional variation in granuloma counts was obsenved from an average of 1.1 per section in the small bowel to 6.1 in the colon, 18.26 in the rectum and 36.1 in the anus. Those patients with a long clinical history showed a low granuloma content.

The results of this study are consistent with the view that the granulomas of Crohn's disease form as a response to a poorly soluble antigenic agent. Patients with many granulomas show a good prognosis, while the disease tends to recur in those with poor granuloma formation. By analogy to leprosy, the tuberculoid variety, with granuloma formation, is associated with a higher degree of cellmediated immunity, and better clinical outlook than the lepromatous form, in which granulomas are not seen. In tuberculosis too, cell-mediated immunity has been shown both in animals and man to be important in resistance, and low resistance is associated with lack of granuloma formation in response to the organism. Experimentally, Boros and Warren ${ }^{6}$ have shown, using Schistosoma eggs, that for antigenic, but not for non-antigenic materials, the cellular immune system converts poor into strong granuloma formation. Assuming, therefore, that the material causing granuloma formation is the same in all cases of Crohn's disease, 
and also assuming normal macrophage function, the results of this study suggest by analogy that the immune system is responsible for converting a diffuse chronic inflammatory reaction into a granulomatous reaction, and this in turn suggests the presence of a poorly degradable antigenic agent, the localisation or elimination of which is improved by granuloma formation.

The large regional variation in granuloma counts from an average of 1.1 in sections of small bowel involved by Crohn's disease, to 36.1 in the anus, may be due to environmental differences-there may be an increasing concentration of granuloma-forming material distally but if this were so, Crohn's disease would be expected to occur more commonly in the same distribution. Alternatively, the difference may be due to differences in tissue susceptibility. The tissue response to the causative agent may be less effective in the terminal ileum than in the distal bowel. The finding of fewer granulomas in the terminal ileum could then reflect this inadequate tissue response and account for the higher incidence of Crohn's disease in the terminal ileum than elsewhere (Morson and Dawson ${ }^{7}$ ). This suggestion is rendered less likely by the observation that the anus, as probably the second commonest site of involvement by Crohn's disease $\left(\right.$ Colcock $\left.^{8}\right)$ has the highest content of granulomas.

\section{REFERENCES}

1. Morson, B C (1974). The technique and interpretation of rectal biopsies in inflammatory bowel disease. From Pathology Annual (1974). Pp. 209-230. Appleton-Century-Crofts, New York.

2. SHove, D C and Morson, B C (1975). Histopathology of rectal biopsies in Crohn's disease. Excerpta Medica International Congress Series No 386, Amsterdam.

3. Dyer, N H, Stansfeld, A G and Dawson, A M (1970). The value of rectal biopsy in the diagnosis of Crohn's disease. Scandinavian Journal of Gastroenterology 5, 491-496.

4. Hywel JoNES, J et al (1973). Numerical taxonomy and discriminant analysis applied to non-specific colitis. Quarterly Journal of Medicine. New Series, XLII, 168, 7.15-732

5. Chambers, T J and Morson, B C (1979). The granuloma in Crohn's Disease. Gut 20, 269-274.

6. Boros, D L and WARRE, K S (1971). Specific granulomatous hypersensitivity elicited by bentonite particles ooated with soluble antigens from Schistosoma eggs and Tubercue bacilli. Nature 229, 200-201.

7. Morson B C and DAwson, I M P (1972). Gastro-intestinal Pathology. Blackwell Scientific Publications, Oxford. P 269.

8. Colcock, B P (1973). Operative technique in surgery for Crohn's disease and its relationship to recurrence. Surgical Clinics of North America 53, 375-380.

\section{Consultant Adviser to the Army}

Col W F Belsham, LMSSA, FFARCS, is appointed Consultant Adviser in Anaesthetics to the Army, in the rank of Brig, in succession to Brig C D Sanders, QHS, LMSSA, FFARCS.

\section{Honorary Consultants}

Dr M M Webb-Peploe, FRCP, was appointed Honorary Consultant in Cardiology to the Army, with effect from 2 October 1978, in succession to Dr W Somerville, MD, FRCP, who has retired. 